\title{
Direito Na Sociedade Da Informação: Paradoxos Da Sociedade Em Rede - Coletividade X Individualismo Nas Comunidades Reais E Virtuais
}

\author{
Ronny Max Machado \\ Mestre em Direito da Sociedade da Informação pelo Centro Universitário das \\ Faculdades Metropolitanas Unidas - São Paulo. E-mail: \\ ronnymaxm@yahoo.com.br
}

\section{Marco Antonio Barbosa}

Doutor em Direito pela Universidade de São Paulo. Consultor do UNICEUB Centro Universitário de Brasília. E-mail: mantobarbosa@gmail.com

\section{Magali Rodrigues de Souza}

Mestre em Direito da Sociedade da Informação pelo Centro Universitário das Faculdades Metropolitanas Unidas FMU de São Paulo. E-mail:

magaly.souzza@gmail.com

Resumo: Visa-se compreender as noções de sociedade em rede, coletivismo, individualismo e os reflexos no direito, discutindo especialmente as ideias de Fritjof Capra e Castells que, através de diferentes abordagens, convergem para o mesmo pensamento de que o mundo seria uma grande rede onde todos estão interligados, em conexões locais, dentro de outras globais, sendo o principal desafio saber qual o papel do direito nesse contexto. O objetivo é investigar esse pensamento na sociedade da informação pelo método da revisão bibliográfica das obras dos autores citados e de outros das áreas das ciências sociais, jurídicas e da ciência da informação. Conclui-se: (i) que as perspectivas desses autores não podem ser definidas como científicas, porque não descrevem ou representam a realidade, mas, ao contrário, enquadram-se na categoria prescritivo-filosófica, por indicarem comportamentos que consideram adequados para um mundo melhor, em suas visões; (ii) diferentemente do pensamento de Fritjof Capra e Manuel Castells, de que todos estão interligados e que são igualmente importantes para a convivência e sobrevivência harmônica e equilibrada, e de que não haveria níveis de superioridade de uns sobre os outros na perspectiva global, no mundo real o que mais se observa é o solipsismo, ainda que se possa admitir a ocorrência de alguma rede virtual efêmera; (iii) no contexto da realidade e não da idealidade dos referidos autores, o papel do direito permanece de difícil precisão ou objetivação, tanto em razão da dificuldade ou impossibilidade de conceituá-lo univocamente, como a teoria piramidal sempre pretendeu, quanto porque ele não apenas se expressa como também é apreendido e utilizado de formas diversas, encontrandose em permanente processo de adequação e modificação, imposto pelos novos desafios da sociedade da informação, não podendo ser coisificado e nas realidades em redes vem sendo chamado a atender novas relações, perspectivas e interesses.

Palavras-chave: Direito. Sociedade da Informação. Teia. Visão Holística Sociedade em Redes.

\section{UNIVERSIDADE FEDERAL DA PARAÍBA}




\title{
Direito Na Sociedade Da Informação: Paradoxos Da Sociedade Em Rede - Coletividade X Individualismo Nas Comunidades Reais E Virtuais
}

\author{
Ronny Max Machado
}

Marco Antonio Barbosa

Magali Rodrigues de Souza

\section{INTRODUÇÃO}

O tema deste estudo concerne às sociedades ou aos modos de organização em rede. A expressão -rede- tem sido empregada por diferentes autores, em diversos campos do saber e com sentidos distintos. Um desses empregos refere-se direta e simplesmente às redes técnicas. Outro emprego concerne ao campo da sociologia da organização. Neste caso, rede pode ser entendida como a maneira informal de associar agentes humanos.

Como sustenta Bruno Latour, a palavra "rede" é tão ambígua que já deveríamos tê-la descartado há muito tempo. Lembra, no entanto, que a tradição dentro da qual ele a emprega permanece distinta, a despeito de sua possível confusão com outras duas linhas. A primeira delas é, obviamente, a rede técnica - eletricidade, trens, esgotos, internet etc. A segunda vem sendo usada, em sociologia da organização, para introduzir uma diferença entre empresas, mercados e países. Neste caso, rede é uma maneira informal de associar agentes humanos (GRANOVETTER, 1985). Para Latour, quando Manuel Castells (2000) usa o termo, os dois sentidos se 
misturam porque rede se torna um modo privilegiado de organização graças justamente ao alcance da tecnologia da informação. Lembra que é também nesse mesmo sentido que Boltanski e Chiapello (2005) se valem da palavra para definir uma nova tendência no modo capitalista de produção.

Como buscar-se-á aprofundar ao longo do presente estudo, o tema redes, além dessas perspectivas acima enunciadas, vêm sendo explorado ainda em outras diferentes áreas do conhecimento, com nuances e enfoques próprios e particulares. Esse é o caso da perspectiva de Fritjof Capara, que desenvolve um pensamento mais geral e filosófico a respeito da vida na Terra. Sua perspectiva pode ser entendida como ecológico-política e seu pensamento como uma travessia transdisciplinar e sistêmica entre ciências naturais e humanas ou sociais, porquanto propõe uma reorientação paradigmática das mesmas (BOEIRA, 2002). Ele sustenta a ligação entre todos os seres e postula modificações no comportamento humano, em uma perspectiva holística ou ecológica, a fim de se garantir a permanência da vida em todas as suas formas. Sustenta também que tanto as sociedades urbanas, assim como os ecossistemas - se tratam de sistemas vivos, dotados dos mesmos princípios de organização, e que podem ser sustentáveis. Pontua que em qualquer sistema vivo há relações de interdependência entre seus componentes, de cooperação generalizada, de reciclagem da matéria, e que o equilíbrio é a sua tendência natural, mas que, porém, a economia e o sistema industrial são lineares. Propõe então, para reverter este quadro, a mudança de paradigmas, a fim de conceber o mundo como um todo integrado, um conjunto de sistemas interconectados, e não como uma coleção de partes dissociadas.

O desenvolvimento do presente artigo parte da análise da obra de Fritjof Capra, objetivando aplicar uma visão, como o próprio autor sugere, holística, entre ela e a obra de Manuel Castells, buscando entender como os dois autores, através de diferentes abordagens, convergem para o mesmo pensamento, qual seja, de que o mundo seja uma grande teia, onde todos estão interligados, 
formando redes de conexões locais dentro de redes maiores - redes globais. Ademais, visa-se compreender ainda, como a atuação do direito nesta que é chamada sociedade da informação pode ser compreendido como atuando em rede, seja local, seja global.

O método é o da revisão bibliográfica crítica e o objetivo é o de contribuir para a produção do conhecimento a respeito do pensamento dos autores Fritjof Capra e Manuel Castells e suas convergências, assim como do pensamento holístico como um todo, especialmente a sua validade e em quais termos para o direito na sociedade da informação.

O artigo está estruturado em seis partes, iniciado por esta introdução. Em seguida, no primeiro item, aborda-se a necessidade de repensar os paradigmas em uma sociedade da informação. Depois, no segundo item, são apresentados os pontos convergentes entre o pensamento de Fritjof Capra e Manuel Castells, sob a denominação de "Um pensamento sistêmico de uma Sociedade da Informação". No terceiro item, discute-se a visão holística aplicada ao direito na sociedade global. Por fim, são apresentadas as considerações finais e as referências.

\section{REPENSAR PARADIGMAS EM UMA SOCIEDADE DA INFORMAÇÃO}

Fritjof Capra (1999) denomina de visão holística a capacidade de enxergar esse todo, complexo, que seria a sociedade em rede. Dentro dessa visão, pretende-se entender o mundo como um sistema constituído por sistemas fechados e abertos e, também, esta lógica sistêmica apreende o mundo como representado por uma relação unificada, na qual cada ação provoca sempre uma reação em cadeia, 
Direito Na Sociedade Da Informação: Paradoxos Da Sociedade

em maior ou menor grau.

Nos dizeres do autor "os problemas não podem ser entendidos isoladamente. São problemas sistêmicos, o que significa que estão interligados e são interdependentes” (CAPRA, 1999, p. 14). Equalizar as relações e os desejos individuais e coletivos, nesta nova sociedade em rede, denominada ainda de sociedade da informação, onde os meios eletrônicos de comunicação são centrais e permitem visualizar esta teia de conexões, parece ser o desafio. Aqui se percebe a importância do direito da sociedade da informação, na medida em que pode ser utilizado como mecanismo apto a intermediar relações e equilibrar interesses individuais e coletivos.

Ainda, segundo Fritjof Capra (1999, p. 14), haveria uma crise de percepção derivada “[...] de uma visão de mundo obsoleta, uma percepção da realidade inadequada para lidarmos com nosso mundo superpovoado e globalmente interligado [...]”. Essa crise de percepção se torna clara ao se observar que o avanço da tecnologia da informação, cujo ícone mais simbólico é a internet que, ao mesmo tempo em que interconecta pessoas, proporciona igual isolamento, de forma que muitos podem pensar que suas ações não se refletem nos outros indivíduos da comunidade, mas, é justamente o oposto que ocorre, pois, a ligação de todos à teia é tal, que qualquer ação em uma de suas pontas, por menor que seja, reflete em toda ela.

Como pontuam Gustavo Cardoso e Manuel Castells (2005, p. 23): "[...] a sociedade em rede é a sociedade de indivíduos em rede", onde cada indivíduo é um nó dessa mesma rede. Portanto, suas ações de alguma forma irão refletir na sociedade. Destarte, faz se necessário pensar em cada ação tomada, com vistas à conservação desse ambiente global onde todos estão inseridos. Do ponto de vista sistêmico, as únicas soluções viáveis seriam segundo Fritjof Capra (1999, p. 15), as soluções "sustentáveis" que para Lester Brown (2000, p. 94): "Uma sociedade sustentável é aquela que satisfaz suas necessidades sem diminuir as perspectivas das gerações futuras”.

Para Fritjof Capra (1999, p. 14), é necessária uma mudança da visão de mundo mecanicista de Descartes e de Newton para uma 
outra visão holística, ecológica, que enfatiza a interdependência de todos os fenômenos, indivíduos e sociedades, que segundo ele, estão encaixados em processos cíclicos da natureza.

No entanto, para enxergar o mundo desta forma, seria necessária a quebra de paradigmas: mudança de valores, de forma a proporcionar equilíbrio dinâmico entre pensamentos e valores, autoafirmação e integração. Pois de acordo com os pensamentos tanto de Fritjof Capra quanto de Manuel Castells para haver uma sociedade sustentável é necessário, primeiramente, uma mudança de paradigma, ou seja: entender que cada parte integra o todo e desta forma, empregar o conhecimento individual em prol do coletivo.

No entanto, cumpre verificar a aplicação prática de tais conceitos, pois, como sustenta Bauman (2001), os indivíduos estão cada vez mais individualistas e são mornos e céticos em relação ao bem-comum.

Em que pese a visão política de Capra não se pode negar que na contramão do que prega, hoje se tem a era digital revestida de ideologias trazidas pela cibercultura (BITTAR, 2019) essas ideologias servem para justificar novos processos sociais e camuflar o surgimento de novos poderes e formas de dominação. Que pretendem que o ser humano, aos poucos, seja substituído por máquinas na visão de Bittar este corpo humano é único nicho de natureza a ser, ainda, substituído no mundo moderno. Não se pode esquecer que de um lado há a necessidade perene de reconexão com a natureza conforme apregoa Capra, mas de outro a humanidade caminha para contrição total deste vínculo substituindo até o próprio ser humano por máquinas. Na visão de Luzia B Silva e Gustavo S. Preussler (2019), essa busca de superação do homem pela máquina é na verdade uma tentativa desenfreada de controle o chamado biopoder, que há muito é citado por Foucault, se transmuta hoje ao que Mbembe (2018) denomina necropoder, o primeiro conceito pega a dominação através do domínio do corpo; já o segundo é na verdade a utilização da morte do ser humano como forma de dominação. A visão de Capra, embora um pouco romântica, pode de fato, ser uma 
das vertentes para se sair deste cenário de dominação.

Embora não se percebam indícios de que essa mudança de paradigma possa ocorrer ao menos em breve espaço de tempo. Embora os pensamentos de Fritjof Capra e de Manuel Castells sejam muito bem articulados, os indivíduos, ao menos em grande maioria, parecem mostrar-se mais egoístas do que altruístas. Destarte, buscase neste estudo melhor conhecer como pode ser compreendido o papel do direito na perspectiva das sociedades ou organização em rede. Seria, talvez, o de possibilitar relações entre indivíduos, grupos e Estados, visando equilibrar disparidades entre os desejos individualistas e o bem-comum?

Fritjof Capra é enfático ao dizer que na atualidade ainda prevalece uma visão obsoleta do mundo, baseada nas ideias cartesianas e mecanicistas de Newton, Descartes e tantos outros cientistas que entendiam o mundo através de cálculos matemáticos, onde tudo ocorreria dentro de um plano de funcionamento mecânico, logo, controlável e previsível. Visão de que era possível ao homem dominar a natureza. Neste mesmo sentido, afirmava René Descartes:

\begin{abstract}
Não admito como verdadeiro o que não possa ser deduzido, com a clareza de uma demonstração matemática, de noções comuns de cuja verdade não podemos duvidar. Como todos os fenômenos da natureza podem ser explicados desse modo, penso que não há necessidade de admitir outros princípios da física, nem que sejam desejáveis (DESCARTES apud CAPRA, 1999 p. $55)$.
\end{abstract}

Tudo indicando que o mundo de hoje não possa mais ser entendido dessa maneira, seja pelas conexões e interconexões que se formaram, seja porque funções matemáticas não são suficientes para esclarecer a complexa relação que se criou ao longo dos anos. A denominada sociedade da informação, com suas formas circulares, onde inexiste começo e fim, na qual as relações virtuais tomam forma e domínio público, onde tudo parece transcorrer de forma transparente é, no entanto, ainda assim, imprevisível. As informações se alastram de maneira vertiginosa e parece não ser possível contê-las, talvez, apenas atenuar suas consequências, mas, 
jamais apagá-las desse "mundo virtualizado".

As afirmações de Fritjof Capra parecem fazer todo sentido; parecendo ser necessário mudar a visão que se tem do mundo. Repensar os paradigmas vigentes até aqui. Mudança de paradigma, para Thomas Kuhn (1996, p. 255), ocorre sob a forma de rupturas descontínuas e revolucionárias.

Já Fritjof Capra (1992, p. 16), por sua vez, partindo do pensamento de Kuhn, adota definição mais ampla para o termo: "Um paradigma, para mim, significaria a totalidade de pensamentos, percepções e valores que formam uma determinada visão de realidade, uma visão que é a base do modo como uma sociedade se organiza".

Justamente, partindo desta visão de Fritjof Capra, que parece se devam repensar os paradigmas que se têm hoje. O individualismo, a necessidade de acumulação de riqueza em detrimento da conservação do meio ambiente e a ideia de que as ações presentes irão impactar somente gerações futuras parecem mostrarem-se obsoletas. Para Fritjof Capra, é necessária então uma mudança de paradigma, para que a sociedade se organize de uma nova maneira, com vistas ao crescimento sustentável, na perspectiva de que cada indivíduo é parte do todo.

O novo paradigma pode ser chamado de uma visão de
mundo holística, - o mundo como um todo integrado e
não como uma coleção de partes dissociadas - ou visão
ecológica, se o termo "ecológica" for empregado num
sentido muito mais amplo e mais profundo que o usual.
Essa percepção ecológica profunda reconhece a
interdependência" (CAPRA, 1999, p. 14).

E para que haja mudança de paradigma, sustenta, é necessária a expansão não apenas de percepções e de maneiras de pensar, mas, também, de valores; os indivíduos devendo adquirir real consciência de que são parte do ambiente, de que suas ações têm reflexos em todos os demais "nós" da grande teia da vida e para que isso ocorra, Fritjof Capra fala em conexão. Para ele, é necessária consciência de que a mudança de valores ocorra com a mudança de pensamento, segundo a velha máxima: pensar global e agir local. 
Deve-se abolir os pensamentos egocêntricos e auto afirmativos e substituí-los por pensamentos colaborativos de integração com a teia, sob grave pena de que, caso contrário, haja colapso ambiental e todos padeçam as consequências.

A conexão nas mudanças entre pensamento e valores, ambas podem ser vistas como mudanças da autoafirmação para a integração. Essas duas tendências - a auto afirmativa e a integrativa - são, ambas, aspectos essenciais de todos os sistemas vivos. Nenhuma delas é, intrinsecamente, boa ou má. O que é bom, ou saudável, é um equilíbrio dinâmico; o que é mau, ou insalubre, é o desequilíbrio - a ênfase excessiva em uma das tendências em detrimento da outra (CAPRA, 1999, p. 18).

Ainda segundo Fritjof Capra (1999, p. 19) “[...] todos os seres vivos são membros de comunidades ecológicas ligadas umas às outras numa rede de interdependências". Assim, indica como necessária mudança na forma de pensar. Um pensamento mais ético e ecológico "[...] essa ética ecológica profunda é urgentemente necessária nos dias de hoje" (BROWN, 2009, p. 24). A mudança de paradigma não é lógica, mas, psicológica, pois a lógica, segundo ele, não é persuasiva, uma vez que é necessária a obediência a normas que por vezes impõem limitações e ou restrições:

\begin{abstract}
A lógica não nos persuade de que deveríamos viver respeitando certas normas, uma vez que somos parte integral da teia da vida. No entanto, se temos a percepção, ou a experiência, ecológica profunda de sermos parte da teia da vida, então estaremos (em oposição a deveríamos estar) inclinados a cuidar de toda a natureza viva (CAPRA, 1999, p. 20).
\end{abstract}

Assim, essa mudança de paradigma deve incluir necessariamente mudança na organização social. Mudança de hierarquias para redes (CAPRA, 1999). Essa mudança consistindo em mudar o velho paradigma baseado em valores antropocêntricos (centralizados no ser humano), para a ecologia profunda, alicerçada em valores "ecocêntricos" (centralizados na Terra) (CAPRA, 1999, p. 19). Sustenta a necessidade de que a noção do bem comum prevaleça sobre as vontades individuais, alinhada ao conceito de redes, mas que extrapole o sentido unicamente virtual ligado à teleinformática e 
adentre o campo "físico" das relações humanas e humanoambientais, com vistas a constituir o pensamento sistêmico, no qual tudo se encontraria intrinsecamente interligado.

\section{UM PENSAMENTO SISTÊMICO DE UMA SOCIEDADE DA INFORMAÇÃO}

A diferença primordial entre o pensamento de Manuel Castells e o de Fritjof Capra em suas definições de sociedade, é que enquanto o primeiro tenta explicar a rede sob o enfoque formal, baseado em conceitos de tecnologia da informação, o segundo, por sua vez, explica o mesmo conceito dentro da lógica empírica da biologia.

Fritjof Capra usa os conceitos biológicos para sustentar que a sociedade humana utiliza o mesmo princípio de organização que qualquer outro reino vivo. Porém, segundo ele, ocorre que o "homem" erra quando tenta ser superior aos demais, ou se imagina mais importante.

Afirma que todos os organismos vivos são igualmente importantes para manutenção do equilíbrio do ambiente, equilíbrio esse fundamental para a manutenção da espécie humana, pois na medida em que o meio ambiente é destruído, as condições, bem como a qualidade de vida, diminuem consideravelmente. Manuel Castells e Gustavo Cardoso afirmam que a sociedade está interligada formando uma grande rede.

As redes são estruturas abertas que evoluem acrescentando ou removendo nós de acordo com as mudanças necessárias dos programas que conseguem atingir os objetivos de performance para a rede. Estes programas são decididos socialmente fora da rede, mas a partir do momento em que são inscritos na lógica da 
rede, a rede vai seguir eficientemente essas instruções, acrescentando, apagando e reconfigurando, até que um novo programa substitua ou modifique os códigos que comandam esse sistema operativo (CARDOSO; CASTELLS, 2005, p. 20).

Os autores, também utilizam da mesma visão da comunidade cientifica, mas com um olhar mais voltado à tecnologia, para argumentar que interligação e interdependência são a lógica da rede.

O que a sociedade em rede é atualmente não pode ser decidido fora da observação empírica da organização social e das práticas que dão corpo à lógica da rede. Assim, irei resumir a essência daquilo que a investigação académica (isto é, a produção de conhecimento reconhecida como tal pela comunidade científica) já descobriu em vários contextos sociais (CARDOSO; CASTELLS, 2005, p. 20).

Tem-se consciência de que não é a tecnologia que forma a sociedade em rede, ela já existia, porém não era visualizada por todos. Sob a ótica de Irineu Barreto Junior (2014), o avanço tecnológico ao longo dos séculos é inconcusso, porém nas últimas décadas sob a égide capitalista, tornou-se a mola propulsora da economia, seja em busca da concorrência, seja pela vantagem competitiva de sua vanguarda.

Manuel Castells salienta que a sociedade em rede - sociedade da informação- é apenas o ponto de partida e que as mudanças e tecnologias a partir dela, serão cada vez mais rápidas e constantes.

\begin{abstract}
A sociedade em rede não é o futuro que devemos alcançar como o próximo estágio do progresso humano, ao adaptarmos o paradigma das novas tecnologias. É a nossa sociedade, em diferentes graus, e com diferentes formas dependendo dos países e das culturas. Qualquer política, estratégia, projeto humano, tem que partir desta base. Não é o nosso destino, mas o nosso ponto de partida para qualquer que seja o "nosso" caminho, seja o céu, o inferno ou, apenas, uma casa remodelada (BARRETO JÚNIOR, 2014, p. 26).
\end{abstract}

Neste sentido, pode-se entender que Manuel Castells compartilha da mesma visão de Fritjof Capra: todos os organismos vivos fazem parte de um todo, as sociedades independentes de cultura ou país estão interligadas, cada ação em um dos nós dessa rede/teia irá refletir em toda ela. Manuel Castells aponta o paradoxo 
existente nessa "nova sociedade": "Vários analistas têm proposto que as sociedades se encontram a viver uma transformação significativa que pode ser caracterizada por duas tendências paralelas que enquadram o comportamento social: individualismo e comunalismo" (CARDOSO; CASTELLS, 2005, p. 3).

Ainda segundo Manuel Castells e Gustavo Cardoso, a sociedade vive um momento de dualidade entre o individualismo e o comunismo. Individualismo porque a cada dia mais pessoas estão preferindo trocar o estresse dos ambientes públicos pela comodidade de suas casas, tendo contato com o mundo apenas através da internet pelas redes sociais, ao mesmo tempo, que compartilham cada detalhe de suas vidas nessas redes, se interligam a várias pessoas, independentemente da localidade e distância que estiverem umas das outras. O espaço parece ser de todos e todos opinam, sobre ele, a sua maneira, daí a ideia de comunismo. Assim, o espaço é ao mesmo tempo circular, pois não se pode determinar seu início ou fim, marcado por um individualismo, na medida em que cada um pode criar seu próprio espaço virtual, e comunista, pois a informação é compartilhada de tal forma que não se pode delimitá-la ou retirá-la por completo desse espaço.

Destarte, a forma que parece mais acertada para se conviver com todos esses antagonismos, associados ao rápido aprimoramento tecnológico e principalmente sobreviver à [...] guerra financeira [...]é o pensamento sistêmico (BURREL; MORGAN 1979, p. 1), segundo aqueles que o adotam ${ }^{1}$. "Os sistemas vivos... [estão] organizados num processo circular causal fechado que leva em consideração a mudança do estado atual das coisas que nos rodeiam na maneira como a circularidade é mantida, mas não permite a perda da própria circularidade" (CAPRA, 1999, p. 89). Assim, o pensamento sistêmico,

${ }^{1}$ É necessário esclarecer que os autores deste artigo não são adeptos da teoria dos sistemas, mas, ao contrário, a dos jogos de linguagem, conforme as teorias de Ludwig Wittgenstein e Jean-François Lyotard. Vide: Ludwig Wittgenstein. Investigações Filosóficas. Trad. José Carlos Bruni. São Paulo, Nova Cultura, 1999 e Jean-François Lyotard. A condição pós-moderna. São Paulo; José Olympio, 2014. 
lança o olhar global ou visão holística, sobre esse mundo que mistura virtual e físico, tentando encontrar o meio termo que equilibre as suas relações de forma a que o virtual não agrida o mundo físico e ao contrário, ajude no desenvolvimento sustentável, na difusão da ecologia, incorporando-se ao ambiente físico (CARDOSO; CASTELLS, 2005).

E concluiu que esse padrão de rede, no qual a função de cada componente é ajudar a produzir e a transformar outros componentes enquanto mantém a circularidade global da rede, é a "organização [básica] da vida" (CARDOSO; CASTELLS, 2005).

Manuel Castells e Fritjof Capra convergem na ideia de que a rede é capaz de se auto reproduzir, pela teoria sistêmica retroalimentar-se. Ambos se utilizam, para tanto, do conceito de autopoiese de Maturama e Varela: "Auto, naturalmente, significa "si mesmo" e se refere à autonomia dos sistemas auto-organizadores, e poiese - que compartilha da mesma raiz grega com a palavra "poesia" - significa "criação", "construção". Portanto, autopoiese significa "autocriação" (ROMESIN; GARCIA, 1997, p. 75). Assim, ambos os autores, compartilham a ideia de que as redes são capazes de se autocriarem, pois, Maturama e Varela supõem que a "[...] autopoiese é um padrão geral de organização comum a todos os sistemas vivos, qualquer que seja a natureza dos seus componentes" (ROMESIN; GARCIA, 1997, p. 75) e ainda que a concepção de autopoiese seja necessária e suficiente para caracterizar a organização dos sistemas vivos, a partir da ótica daqueles que assim entendem.

No entanto, Fritjof Capra vai um pouco mais longe ao afirmar que apesar dessa capacidade de autocriação, os recursos nem sempre são renováveis, pois possuem natureza transitória e efêmera. Assim, a única forma de manter um ambiente adequado à vida exige que se entenda essa mutação constante e que se tenha consciência de que muitos recursos não são renováveis, sendo necessário um olhar mais ecológico no sentido de sustentabilidade. Produzir e reproduzir sem, no entanto, esgotar o recurso básico necessário para esta renovação.

Não se pode, porém, esquecer a crítica à corrente do 
desenvolvimento sustentável.

A crítica dessa corrente ao Desenvolvimento Sustentável (DS) é ferina, por considerá-la um puro contrassenso, uma ideologia simplificadora do real, uma simples "tentativa sedutora de salvar o crescimento" (Latouche, 2007, p. 113). Morin (2007, p.75), que não pertence a esse movimento, embora nutra por ele simpatia, também não poupa críticas ao DS, para ele "o desenvolvimento sustentável nada mais faz do que temperar o desenvolvimento por meio da consideração ecológica, mas sem questionar seus fundamentos" (NASCIMENTO, 2012, p. 60, grifo do autor).

Para Serge Latouche (1986), o mais radical dos defensores do decrescimento, o modelo atual de produção e consumo não tem futuro, porque conduz à auto extinção e indica como única saída para a humanidade a adoção de valores e costumes novos, "[...]com abandono da moda, do instantâneo, em troca de uma produção duradoura e decrescente. Enfim, adoção de um novo estilo de vida” (NASCIMENTO, 2012, p. 61).

É possível assim verificar que mesmo as ideias de ecologia e de sustentabilidade compreendidas no pensamento de Fritjof Capra são problemáticas e sujeitas a severas críticas, sendo que, nesta altura do presente estudo, não se pode deixar de assinalar que o seu pensamento se enquadra enquanto teoria moral ou ética, prescritiva, portanto, parcial e não sociológica, no sentido de que não se trata de uma descrição da realidade empírica, mas de uma postura de dever ser, portanto, não científica.

\section{NECESSIDADE DE UMA VISÃO HOLÍSTICA DO DIREITO NA SOCIEDADE GLOBAL?}

Em "O ponto de mutação", Fritjof Capra explica o termo holismo: "Holismo" (do grego holos que significa inteiro ou todo) (CAPRA, 1998, p. 6), ou seja, não é possível compreender as partes 
separadamente, é preciso entender que cada parte compõe o todo. E, as partes, só podem ser entendidas se observadas a partir desse todo. Smuts define o Holismo "[...] como uma tendência sintética do universo em evoluir por meio da formação de todos”. Para ele, a evolução poderia ser compreendida como o desenvolvimento destas partes que compõem o todo. E afirma ainda que o desenvolvimento ocorre de forma gradual, mas "atinge" todos os componentes desse todo - sistema-, em todos os níveis, seja moral, tecnológico ou religioso.

A criação de todos no universo é um fator operativo fundamental enunciado pelo Holismo. Qualquer organismo é um todo que apresenta um padrão de organização interno. Isto se dá desde os mais simples microrganismos, até a formação da complexa personalidade humana. Por essa visão: 'todos' são básicos para o caráter do universo, e o Holismo, como fator operacional na evolução dos todos, é o princípio decisivo do universo (SMUTS, 1996, p. 98, tradução pessoal).

Em A teia da vida e em O ponto de mutação, Fritjof Capra explana sobre a distinção entre "holístico" e "ecológico" e afirma que para a mudança de paradigma proposto a visão holística não seria a mais adequada:

\footnotetext{
"Holístico" é um pouco menos apropriado para descrever o novo paradigma. Uma visão holística, digamos, de uma bicicleta significa ver a bicicleta como um todo funcional e compreender, em conformidade com isso, as interdependências das suas partes. Uma visão ecológica da bicicleta inclui isso, mas acrescenta-lhe a percepção de como a bicicleta está encaixada no seu ambiente natural e social - de onde vêm as matérias-primas que entram nela, como foi fabricada, como seu uso afeta o meio ambiente natural e a comunidade pela qual ela é usada, e assim por diante. Essa distinção entre "holístico" e "ecológico" é ainda mais importante quando falamos sobre sistemas vivos, para os quais as conexões com o meio ambiente são muito mais vitais (CAPRA, 1999, p. 17).
}

Fritjof Capra segue explicando a diferença entre a ecologia rasa que julga antropocêntrica, ou centralizada no ser humano, como se este estivesse situado acima ou fora da natureza e a ecologia profunda que não separa seres humanos, ou qualquer outra coisa, do 
meio ambiente natural. Sustenta que há conexão entre todas as partes: "O Mundo não como uma coleção de objetos isolados, mas como uma rede de fenômenos que estão fundamentalmente interconectados e são interdependentes” (CAPRA, 1999, p. 16).

$\mathrm{Na}$ visão de Fritjof Capra, a ecologia profunda reconhece o valor intrínseco de todos os seres vivos e concebe os seres humanos apenas como um fio particular na teia da vida. Chama a nova visão emergente da realidade, de "ecológica" no sentido da ecologia profunda e enfatiza que a vida se encontra em seu próprio cerne.

No velho paradigma, a física foi o modelo e a fonte de metáforas para todas as outras ciências. "Toda a filosofia é como uma árvore", escreveu Descartes. "As raízes são a metafísica, o tronco é a física e os ramos são todas as outras ciências"2. A ecologia profunda superou essa metáfora cartesiana. Hoje, a mudança de paradigma na ciência, em seu nível mais profundo, implica uma mudança da física para as ciências da vida (CAPRA, 1998, p. 63).

Assim, para se conceber um novo paradigma, nessa perspectiva, é necessário que se tenha uma visão holística, ou melhor ainda, ecológica. Entendendo que cada parte integra o todo, integrando-se nele totalmente, onde nenhuma parte é melhor ou mais importantes que outras, tudo e todos são necessários para manter o equilíbrio desse mesmo todo.

A fim de não ficar apenas no plano das ideias, é adequado lembrar as conclusões de Elimar Pinheiro do Nascimento, em seu artigo já citado sobre a trajetória da sustentabilidade (NASCIMENTO, 2012) no qual lembra a persistência do embate entre visões dos países desenvolvidos e daqueles em desenvolvimento ou subdesenvolvidos, anunciado já nos anos de 1970. Porém, agora, em contexto diferenciado, porque a questão ambiental não apenas se ampliou como ganhou novas conotações, a partir do relatório do IPCC (Painel Intergovernamental sobre Mudanças do Clima) de 2007. Segundo ele, as diferenças residem 
principalmente em dois pontos. Primeiro, que a crise ambiental assumiu proporções muito mais graves com a percepção da responsabilidade humana pelo aquecimento global e o aumento significativo do contingente humano no mercado de consumo. Segundo, fortalecimento das propostas de desenvolvimento sustentável, sob a roupagem da economia verde.

Mudanças devidas à localização de fontes fósseis fora de seus territórios vêm obrigando alguns países desenvolvidos a investir em novas fontes energéticas, tendo o recente acidente nuclear no Japão estimulado ainda mais esse movimento, associadas cada vez mais às inovações tecnológicas, o que cria a possibilidade de nova onda de inovação de longa duração. "Assim, a economia aproxima-se ainda mais da atitude de poupar o meio ambiente nos países desenvolvidos e ganha maior relevância nos países em desenvolvimento" (NASCIMENTO, 2012, p. 61).

Por sua vez, a dinâmica econômica dos países em desenvolvimento, retirando parte de suas populações que estão abaixo da linha da pobreza, associada a uma percepção mais pessimista da crise ambiental, muda o enfoque do combate à pobreza. A questão é saber se ocorrerá um movimento no sentido de retirar do desenvolvimento sustentável a centralidade do social em direção ao ambiental. A fusão do eixo do combate à pobreza com a economia verde na Rio+20 parece indicar algo nesse sentido, assim como um novo "casamento" entre economia e meio ambiente. São todos, porém, movimentos débeis que ainda não se tornaram tendências vigorosas. Como dissemos em outro momento (Nascimento \& Andrade, 2011), o século XXI nasceu sob três signos: da contradição, da incerteza e da esperança. A contradição entre os indícios de crescimento da crise ambiental e a fragilidade das medidas adotadas; a incerteza quanto ao futuro da humanidade no acirramento das crises econômica e ambiental; e a esperança de que transformações sociais ocorram, mudando - para melhor - o padrão civilizatório a que estamos prisioneiros, como quer Morin (2011) (NASCIMENTO, 2012, p. 62).

Neste ponto parece ser bem adequado buscar estabelecer conexão com o direito da sociedade da informação, a partir, inicialmente, do questionamento se ele pode ser compreendido enquanto mecanismo para intermediar, arbitrar, essas relações paradoxais e heterogêneas, que o desafiam a desempenhar papel ao 
mesmo tempo global e local.

O papel global configura-se na medida em que é chamado tanto a sustentar direitos humanos, ambientais, coletivos, privados, econômicos etc. Já o papel local se apresenta na medida em que é convocado a resolver conflitos novos e das mais diferentes ordens e a se flexibilizar frente à realidade contingente. $\mathrm{O}$ direito, assim como os próprios homens, grupos e sociedades é permanentemente desafiado a se adaptar às questões e fatos da sociedade global diuturnamente lançados.

\begin{abstract}
As teorias da "sociedade em rede", como a que desenvolveu, por exemplo, Manuel Castells, veem as redes de atores coletivos por toda a sociedade como a característica distintiva de sociedades pós-modernas e identificam as "falhas na rede" como riscos sociais graves (Castells, 2000; Weyer, 2011). As formas de direitos fundamentais estão sendo ameaçadas de extinção nas esferas não governamentais, em mercados, organizações e redes. Não é apenas uma questão que diz respeito a juristas, mas também uma questão levantada por várias teorias sociais, por exemplo, a sociologia constitucional de Chris Thornhill; este é um fenômeno atribuído a tendências expansionistas de atores coletivos não governamentais (Thornhill, 2013) (TEUBNER, 2015, p. 77).
\end{abstract}

Também para Taubner, a sociedade em rede, segundo as diferentes teorias sociais, entre as quais cita expressamente a de Manuel Castells, apresenta-se enquanto atores coletivos, presentes em toda a sociedade pós-moderna. Para ele, nas teorias relativas às sociedades em rede, "falhas na rede" constituem-se em riscos sociais graves e que por isso mesmo as formas de direitos fundamentais estariam sendo ameaçadas de extinção dado ao expansionismo dos atores coletivos não governamentais, em mercados, organizações e redes (TEUBNER, 2015, p. 77). Nesse ambiente enumera alguns problemas que chama de espinhosos, relativamente à prática do direito. Em primeiro lugar aponta a concorrência entre as teorias sociais e se pergunta como o direito deveria fazer uma seleção entre elas se são concorrentes e conduzem à análise de redes incompatíveis entre si, ou, simplesmente, não concordam sobre a validade e o efeito dos direitos fundamentais em face de atores coletivos não 
governamentais. Sobre esse ponto indica como caminho para o direito o emprego da transversalidade3. Em segundo lugar, trata da transferência de conhecimento e pergunta se é possível implantar padrões de direitos fundamentais adequados às redes, bem como se as teorias sociais podem orientar a seleção de sanções contra violações de direitos fundamentais para que possam ser eficazes diante da lógica própria das redes. Como resposta, indica a necessidade de responsividade4. Em terceiro lugar, questiona se critérios normativos para os direitos fundamentais em redes mistas público-privadas (PPP) podem ser derivadas de teorias sociais. Como resposta indica a autonormatividade5.

Não há mais uma teoria da sociedade, mas apenas teorias de campos parciais igualmente justificadas. No entanto, cada uma delas -e isso é o que causa preocupação- reivindica, ao mesmo tempo, validade universal como a única teoria da sociedade. Este é o paradoxo -uma multiplicidade de racionalidades parciais com reinvindicações totalitárias- que o direito deve enfrentar hoje, se almeja obter uma orientação das

\footnotetext{
3“Somente na análise transversal de outras teorias sociais torna-se claro que o novo conceito legal de finalidade da rede cobre uma área de complexidade maior do que qualquer mera minimização de custos da transação [conforme a teoria econômica de custos]. Ele [o direito] deve ser compreendido como uma orientação múltipla, que incorpora, por um lado, um compromisso com os vários projetos individuais dos participantes da rede e, por outro, com o projeto global da rede como um todo (TEUBNER, 2015, p. 83)". Assim cabe ao direito entender as redes intersistêmicas como arranjos organizacionais "nos quais o conflito entre diferentes racionalidades sociais é, na verdade, institucionalizado. Um conceito jurídico de finalidade da rede que é definido dessa forma obriga os atores a ajustarem seu comportamento a lógicas de ação diferentes e contraditórias (TEUBNER, 2015, p. 84)”.

4"A responsividade do direito não deve ser julgada perante um fórum das ciências sociais que pudesse garantir o uso autêntico do termo, ou perante um fórum de uma terceira instância superordenadora que agiria como intermediária entre o direito e a teoria social, mas apenas perante o forum internum do próprio direito. Em um exame complexo, o direito deixa-se desafiar pelas análises externas de problemas das teorias sociais, mas isso apenas se elas são passíveis de utilização conforme os próprios critérios de seleção do direito; então, ele as reconstrói internamente em sua própria língua, na qual ele pode, assim, conciliar problemas e soluções entre si. Somente quando esse processo de reconstrução coloca a argumentação jurídica em uma posição na qual ela possa distinguir dentro do direito entre normas e fatos, entre conceitos jurídicos e interesses sociais, é que se alcança um ponto no qual o direito é capaz de levantar a questão da adequação social, em outras palavras, a questão de saber se as decisões judiciais fazem justiça a esses aspectos do mundo exterior, tal como estes foram reconstruídos internamente (TEUBNER, 2015, p. 87)".

5"Autonormatividade: o direito não alcança a orientação normativa a partir da teoria social, mas unicamente de processos internos a ele e, ao mesmo tempo, a partir da autonormatividade desenvolvida pelas dogmáticas de reflexão de outros sistemas sociais (TEUBNER, 2015, p. 95)”.
} 
teorias sociais (TEUBNER, 2015, p. 79).

Mais adiante, questiona se um direito de redes pode responder a tais desafios. "Em vez de simplesmente promover a minimização dos custos da transação, uma constituição legal de redes terá que desenvolver princípios de autonomia institucional, direitos fundamentais, imparcialidade processual e regras de direito e de responsabilidade política, para esse misto de configurações público-privadas” (TEUBNER, 2015, p. 84).

Assim, segundo Teubner ainda, a forma jurídica da rede não deve reconhecer qualquer teoria social como detentora de monopólio. Não deve haver exclusividade seja para a redução de custos da transação, seja para a orientação política, seja para a aquisição de conhecimento científico, ou, seja ainda para padrões éticos de comportamento. Cada uma desses objetivos correspondendo ao de uma das diversas teorias sociais, que na sua visão, como já referido, é sempre parcial. Assim, a forma legal, na sua proposta, deve buscar "[...] cobrir a multidimensionalidade das redes, explorando as diferentes teorias sociais. É vedado ao direito aceitar o domínio de qualquer racionalidade social parcial” (TEUBNER, 2015, p. 84). Afirma ainda, que no caso das redes intersistêmicas ${ }^{6}$ há muito mais em jogo, pois nelas não é apenas a aquisição de lucro que pode ser considerada a finalidade legal da rede. Nessas, há a necessidade também, de considerar a integridade das instituições de pesquisa, das instalações médicas, dos investidores privados e da administração pública, e a própria estrutura descentralizada da rede.

Ao contrário da finalidade do contrato ou da finalidade social, a finalidade da rede impõe a obrigação de promover as diferentes racionalidades envolvidas e, ao

\footnotetext{
${ }^{6}$ Segundo o autor as redes corporativas são redes exatamente da mesma maneira que as redes contratuais, mas não integram o conjunto do que denomina de redes intersistêmicas. Nesses casos, além das garantias legais de autonomia das subsidiárias, também protegem os interesses puramente econômicos das subsidiárias contra a matriz e vice-versa. $\mathrm{O}$ exemplo que analisa no artigo em referência, refere-se às redes intersistêmicas, compostas de participantes públicoprivadas (PPP), concernente à pesquisa e à produção de produtos farmacêuticos.
} 
mesmo tempo, equilibrar umas às outras. Em contraste com o equilíbrio tradicional de interesses no caso individual, o resultado da abordagem da transversalidade seria o de que diferentes racionalidades sociais seriam examinadas em um processo de equilíbrio (TEUBNER, 2015, p. 85).

Assim, flexibilização e adaptação, não quer dizer que o direito deve sucumbir aos dilemas ou às teorias sociais, tal como são formuladas no campo da própria teoria social. Teubner (2015) oferece como alternativa o emprego da transversalidade, responsividade e da autonormatividade, com as conotações já expostas anteriormente. Para atuar nessa sociedade em rede, sem se submeter a "teorias sociais totalitárias", como denomina todas elas, é necessário, segundo o autor, que o direito adote a perspectiva transversal, levando em conta as diferentes teorias sociais, entendoas como parciais, flexibilizando-se para atender às novas e diferentes demandas desta sociedade em rede, sem, no entanto, sucumbir, inteiramente, a nenhuma delas. O direito deve ao mesmo tempo estar presente nessa nova sociedade global, organizada em rede, e definida como sociedade da informação, mas mantendo certo distanciamento que o impediria de se "contaminar" com "teorias" parciais que levariam a sociedade como um todo à falência de suas instituições. Esse é o aspecto que denominada de transversalidade. Ademais, impõe-se a "responsividade" (TEUBNER, 2015), entendida com a ação de compatibilização dos interesses públicos e privados desta rede, na busca de equilibrar a convivência dos envolvidos.

Para tanto, os implicados na rede devem ainda recorrer à auto normatividade (TEUBNER, 2015), entendendo que "[...] o direito não alcança a orientação normativa a partir da teoria social, mas unicamente de processos internos a ele e, ao mesmo tempo, a partir da autonormatividade desenvolvida pelas dogmáticas de reflexão de outros sistemas sociais" (TEUBNER, 2015, p. 95).

Assim, a visão holística de Fritjof Capra, na análise de Taubner, pode ser compreendida como uma teoria suportada em critérios morais, baseada na "[...] forma de interações específicas como prova de apreço mútuo”. Ela inclui-se entre as teorias sociais 
baseadas em critérios da filosofia moral que "[...] reivindicam a soberania regulamentadora sobre questões e demandas sociais (hoje em dia, principalmente a ecológica) a serem implementadas na forma de normas jurídicas" (TEUBNER, 2015, p. 79) de modo que, entender o direito por meio dessa perspectiva social (a ecológica ou holística) parece mostrar-se insatisfatória, justa e precisamente por ser uma teoria social parcial e de cunho moral, sobretudo, lembrando que se trata o direito de uma instituição heterogênea, assim como heterogêneas também são outras instituições sociais, como a política, a ciência, ou mesmo a religião, compreendidas todas elas, na perspectiva de Bruno Latour, como regimes de enunciação7. Não se podendo, pois, querer perceber e tratar o direito, antecedido do artigo definido "o", pois, seria o mesmo que exigir

[...] a passagem do um ao muitos que seria impraticável: exigiríamos da ordem dada que ela fosse exatamente, diretamente, fielmente transportada sem traição, deformação, viés ou tradução! Pediríamos que a ordem fosse executada sem acréscimo, nem subtração. Sabemos que isso é impossível, porque os humanos, como nos ensinou Ludwig Wittgenstein, não seguem jamais as regras, mas "bordam" sobre o desenho que elas fornecem (LATOUR, 2004, p.13)

Assim, perceber o direito no contexto das redes invoca os regimes de enunciação, de modo que se deve procurar identificá-lo a partir de mediações práticas, sem o apelo a explicações institucionais, como normalmente ocorre para tentar especificar o que ele seja e o que não seja.

\section{CONSIDERAÇÕES FINAIS}

\footnotetext{
7 Latour (2004, p. 13) chama de regimes de enunciação, procurar nos modos de desenvolvimento e de desdobramento das mediações a fonte dos tipos de coordenação, que se abstém de toda explicação social para fazer emergir as formas de coordenação a partir das mediações práticas. Os sociólogos dessa corrente, segundo Latour, filiados a Gabriel Tarde e não a Émile Durkheim, e que os chama de sociólogos da associação, ou da tradução, ou ainda da enunciação.
} 
Como foi possível perceber ao longo deste estudo, a expressão rede, tem sido empregada por diferentes autores e em diferentes campos do saber. Um emprego se refere simples e diretamente às redes técnicas - eletricidade, internet etc. Outro, em sociologia da organização, basicamente para determinar diferença entre empresas, mercados e países. Neste caso, rede pode ser entendida como a maneira informal de associar agentes humanos. Inscreve-se no debate a respeito de alternativas às ditas "abordagens representacionais" nos estudos das organizações. Nessas discussões destaca-se o aspecto processual e fluido da organização. Insiste-se que ela não pode ser tomada como um fim ou um objeto estático, exigindo outras formas de explorar e compreender seu fenômeno. Abordagem que adquiriu grande popularidade foi a Teoria AtorRede (TAR), objeto de diversas críticas, a principal seria uma suposta falta de potencial político e/ou crítico, sendo John Law, o autor mais destacado nos estudos organizacionais, a partir de estudos empíricos e que se contrapõe às principais críticas referidas.

Já Manuel Castells parece usar o termo nos dois sentidos. No seu caso, rede se torna um modo privilegiado de organização, graças, precisamente, ao alcance da tecnologia da informação, sendo nesse mesmo sentido que outros autores, como Boltanski e Chiapello (2005) usam o termo para definir uma nova tendência no modo capitalista de produção.

Fritjof Capra, por sua vez, sustenta que tanto as sociedades urbanas, assim como os ecossistemas - são sistemas vivos, dotados dos mesmos princípios de organização, e que podem ser sustentáveis. Ele pontua que em qualquer sistema vivo há relações de interdependência entre seus componentes, de cooperação generalizada, de reciclagem da matéria, e que o equilíbrio é a sua tendência natural, mas que, porém, a economia e o sistema industrial são lineares. Propõe então, para reverter este quadro, a mudança de paradigmas, a fim de conceber o mundo como um todo integrado, um conjunto de sistemas interconectados, e não como uma coleção de partes dissociadas. 
Ao término desta análise, é possível perceber que os dois autores Fritjof Capra e Manuel Castells convergem para a mesma ideia de que todos estariam interconectados por um emaranhado invisível de conexão, mas real. Para Manuel Castells cada indivíduo é um nó dessa rede, talvez, uma das principais diferenças em suas abordagens - um olhar mais atento possibilita perceber - que Manuel Castells enfatiza o indivíduo como principal componente da rede, e que a rede constitui-se na conexão de vários indivíduos, e o ambiente serve de cenário para a formação da rede, e se utiliza de conceitos da tecnologia da informação para demonstrar os seus próprios conceitos, embora deixe claro que esta rede existe independente da evolução da informática e que o meio ambiente é igualmente importante para a manutenção do ambiente de rede, sem o qual a existência dos indivíduos não seria possível. Já Fritjof Capra, por sua vez, dá ênfase ao meio ambiente. Afirma que não existe grau de superioridade, considerando tudo e todos como importantes para a manutenção da teia da vida e que o meio ambiente e os indivíduos, como partes inextricáveis do ambiente são igualmente importantes, não se podendo estabelecer prioridades entre eles.

Mas, os seres humanos teriam a obrigação de manter o meio onde vivem, sendo preciso, para tanto, a plena consciência de sua necessidade (do meio ambiente) para a sobrevivência de toda a espécie humana e também das outras formas de vida e do planeta, ameaçados todos pela ação antrópica. Ambos os autores convergem ainda, quando afirmam que há necessidade de consciência por parte de todos sobre essas ligações em rede/teia, pois, todas as ações de cada indivíduo/nó irão refletir, em maior ou menor grau, em todos os outros indivíduos e espécies vivas, bem como sobre o meio ambiente, e em última análise, refletirá sobre o próprio agente.

Conclui-se ainda que o ponto de convergência entre Fritjof Capra e Manuel Castells está na visão de que a sociedade como um todo está interligada e mais, que ela existe como unidade. Fritjof Capra apresenta uma visão mais humanista voltada à biologia e à preservação ambiental e defende o crescimento sustentável. Já 
Manuel Castells, por sua vez, adota visão mais empresarial da sociedade e defende que a sociedade em rede é flexível, portanto, adaptável; sendo assim, seria capaz de usar seu conhecimento e cultura em prol do desenvolvimento econômico, com vistas à preservação da natureza como recurso necessário à manutenção da vida, ou seja, desta rede.

No entanto, em que pese toda a argumentação de ambos os autores, ela não passa de uma filosofia moral à qual as sociedades, os indivíduos e todos os diferentes e divergentes agregados sociais humanos de hoje, ainda não atendem aos seus postulados éticos, a ponto de se poder obter a unicidade de visão que a proposta sugere, e constituir-se assim uma comunidade global uma sendo que a própria ideia de unidade, implicada nessa filosofia moral, por melhor intencionada que possa soar, sugere, uma forma de pensamento totalitário. O mundo virtual e o real, parecem não convergir em quase nenhum ponto, pois, virtualmente, o conceito de comunidade extraterritorial e globalizada, parece largamente aceito, mas, ele não se transporta para o mundo real. $\mathrm{O}$ individualismo nesses dois mundos parece sempre preponderar, bem como os comportamentos coletivos mostram-se frágeis e provisórios.

Diante desta conclusão é preciso adicionar outra e que se refere ao o direito nesse mundo em rede, o qual não se encaixa na perspectiva do modelo clássico ou piramidal da teoria jurídica moderna, cuja lógica decorre necessariamente do Estado. Esse direito no mundo em rede, não pode ser tratado no singular ou na perspectiva da unidade, igualdade e homogeneidade, como sempre insistiu a teoria clássica. Ele deve ser visto e estudado na perspectiva da diferença, principal fator a ser reconhecido como caracterizador da condição humana e do próprio direito, permanentemente desafiado à adaptação e à flexibilização com vistas a responder aos inúmeros, permanentes e diversos encontros e conflitos ocorrentes neste novo momento dos diferentes, frágeis e provisórios agregados sociais. Constrói-se e se reconstrói em permanência a partir de mediações práticas dinâmicas. 
No caso deste estudo, especialmente das próprias relações estabelecidas na rede, e justamente por isso, o direito é tão complexo e inovador quanto ela. Direito, assim como rede é conceito, não coisa, como já muito bem asseverou Bruno Latour, em relação às redes. Deve ser tratado antes como ferramenta que nos ajuda a descrever algo e não como algo que esteja sendo descrito. Portanto, direito em rede não se confunde com o quadro no qual há tanto tempo tem sido encerrado pela teoria clássica ou piramidal, a qual, de maneira alguma funciona no conceito de rede, porque concebida como superfície, instituição, como conjunto estabilizado. Ao contrário, Direito em rede, remete antes a mediações ativas, a rede de ações.

Data de Submissão: 08/09/2018

Data de Aprovação: 27/09/2019

Processo de Avaliação: double blind peer review

Editor Geral: Jailton Macena de Araújo

Editor de Área: Jailton Macena de Araújo

Assistente Editorial: Jaqueline Rosário Santana

\section{REFERÊNCIAS}

BARRETO JÚNIOR, Irineu Francisco. Paradoxos entre regulação da mídia e liberdade de expressão na sociedade da informação. In: Anais do VII Congresso Brasileiro de Direito da Sociedade da Informação. 2014. p. 23-30.

BAUMAN, Zygmunt. Modernidade Líquida. Tradução Plínio Dentzien. Rio de Janeiro: Jorge Zahar, 2001. p.50. 
Direito Na Sociedade Da Informação: Paradoxos Da Sociedade

BITTAR, Eduardo CB. A Teoria do Direito, a Era Digital e o PósHumano: o novo estatuto do corpo sob um regime tecnológico e a emergência do Sujeito Pós-Humano de Direito. Revista Direito e Práxis, v. 10, n. 2, p. 933-961, 2019.

BOEIRA, Sérgio Luís. Ecologia política: Guerreiro Ramos e Fritjof Capra. Ambiente \& Sociedade, n. 10, p. 1-21, 2002.

BOLTANSKI, Luc; CHIAPELLO, Eve. The New Spirit of Capitalism, trans. G. Elliott (London and New York: Verso), 2005.

BOLTANSKI, Luc; CHIAPELLO, Eve. The new spirit of capitalism. International journal of politics, culture, and society, v. 18, n. 3-4, p. 161-188, 2005.

BROWN, LESTER R.; Plano B 4.o: mobilização para salvar a civilização. São Paulo: New Content, 2009.

BROWN, LESTER. Estado do Mundo, 2ooo. Salvador: UMA Ed., 2000.

BURREL, G; MORGAN, Gareth. Sociological Paradigms and Organizational Analysis. Heineman, London, 1979.

CAPRA, Fritjof. A teia da vida. Tradução. Newton Roberval Eichemberg. São Paulo: Editora Cultrix, 1996.

CAPRA, Fritjof. O Ponto de Mutação. Trad. Álvaro Cabral. São Paulo: Editora Cultrix, 1998.

CAPRA, Fritjof. Sabedoria incomum. Tradução Carlos Afonso Malferrari. São Paulo: Editora Cultrix, 1992.

CARDOSO, Gustavo; CASTELLS, Manuel. A sociedade em rede: do conhecimento à acção política. Imprensa Nacional-Casa da Moeda: Belém-Portugal, 2005.

CASTELLS, Manuel, A. Sociedade em Rede. "Tradução de Roneide Venâncio Majer." São Paulo, Editora Paz e Terra ,1999.

DA SILVA, Luzia Bernardes; DE SOUZA PREUSSLER, Gustavo. Necropolítica: biopoder, soberania, estado de exceção, política da morte. Revista Eletrônica PRIM@ FACIE. João Pessoa: PPGCJ, v. 18, n. 37, 2019.

DESCARTES, René; CIVITA, Victor Discurso do método:

Meditações: Objeções e respostas: As paixões da alma; Cartas. Abril Cultural, 1973. 


\section{GETSCHKO. Demi. A influência da tecnologia digital no}

direito da sociedade da informação. Palestra proferida 31.03.17 pelo programa de mestrado em Direito na Sociedade da Informação do Centro Universitário das Faculdades Metropolitanas UnidasFMU.

GRANOVETTER, Mark. Economic action and social structure: the problem of embeddedness. American Journal of Sociology, Chicago, v. 91, n. 3 , nov. 1985 .

KHUN, Thomas S. A estrutura das revoluções científicas. Tradução Beatriz Vianna Boeira e Nelson Boeira; Revisão: Alice Kyoto Miyashiro; Produção: Ricardo W. Neves e Adriana Garcia. São Paulo: Ed. 1996.

LATOUR, Bruno. Se falássemos um pouco de política? Revista Sociologia, 2004, p.11-40.

LISBOA, Roberto Senise. Direito na sociedade da informação. Revista dos Tribunais, ano, v. 95, p. 106, 2006.

MBEMBE, Achille. Politiques de l'inimitié. La découverte, 2018.

NASCIMENTO, Elimar Pinheiro. Trajetória da sustentabilidade: do ambiente ao social, do social ao econômico. Estudos Avançados, 26 (74), 2012, p. 51-64.

NIETZSCHE, Friedrich. Cinco prefácios para cinco livros não escritos. Tradução Felipe Sussekand. Rio de Janeiro 7 Letras, 2007.

ROMESIN, Humberto Maturana; GARCÍA, Francisco J. Varela. De máquinas e seres vivos, autopoiese: a organização do vivo. (Trad. Juan Acunã Llorens) Porto Alegre: Artes Médicas, 1997.

SMUTS, J. C. (1996). Holism and evolution. New York: The Gestalt Journal Press (Original de 1926).

TEUBNER, Gunther. Direito e teoria social: três problemas. Tempo Social, v. 27, n. 2, p. 75-101, 2015. 


\title{
Law In The Information Society: Paradoxes Of Network Society - Collectivity X Individualism In Real And Virtual Communities
}

\author{
Ronny Max Machado
}

Marco Antonio Barbosa

Magali Rodrigues de Souza

\begin{abstract}
This study aims to understand the role of law in the information society, questioning the ideas of Fritjof Capra and Manuel Castells. The two authors, using different approaches, converge to the same thought, that is, the world is a great Web where all is interlinked, forming networks of local connections in larger networks-global networks. The goal here is to investigate the validity of this thought in the information society. The challenge is, leaving this thought, learn how the right can help to standardize and regulate the coexistence and participation of individuals in this networked society or what your role within this global society. Through the literature review, the authors cited and several works of law and the information society, it was realized that the role of the law is to harmonize and balance the coexistence, understanding the relationship and need between the two premises, increasingly in this immensely heterogeneous network perennial; It also has the role of guardian and protector of the right to life, human dignity and the environment; and yet, that diverges from the thought of Fritjof Capra and Manuel Castells, that all are interconnected, which are equally important to a balanced and harmonic coexistence and survival, and there are no levels of superiority of some over others; since despite the validity of these concepts, the society still doesn't have this ability to think globally; Unlike the information society is the society of isolated individuals, albeit recklessly can be part of any virtual network and ephemeral; There is therefore the need of law and persist to regulate relations between individuals.
\end{abstract}

Keywords: Law. The information society. Web. Holistic networking Society. 